\title{
The influence of top-down expectations on the perception of syllable prominence
}

Denis Arnold and Petra Wagner

Institute of Communication Sciences, University of Bonn, Germany

https://doi.org/10.36505/ExLing-2008/02/0007/000066

\begin{abstract}
In our study we use the experimental framework of priming to manipulate our subjects " expectations of syllable prominence in sentences with a welldefined syntactic and phonological structure. It shows that it is possible to prime prominence patterns and that priming leads to significant differences in the judgment of syllable prominence.
\end{abstract}

Key words: top-down, priming, syllable prominence, perception

\section{Introduction}

Experimental phonetics has long sought to define accurate acoustic correlates of syllable prominence. Findings of several studies e.g. Eriksson (2001), Wagner (2005), indicate that syllable prominence ratings can be affected by top-down processes in addition to acoustic cues. However, a systematic investigation such influences has not been carried out yet. In our study we use the experimental framework of priming to manipulate our subjects' expectations of syllable prominence in sentences with a welldefined syntactic and phonological structure. We examine if priming leads to different ratings of syllable prominence thus gaining better insight into the role that top-down expectations play for the perception of syllable prominence.

We describe two experiments. The first experiment uses an intraindividual design. Due to some problems, we carried out a second experiment with a interindividual design with four groups.

\section{Experiment 1}

32 subjects were asked to rate the syllable prominence of 44 sentences presented via headphones with the help of ten sliders on a computer screen (cf. Fig. 1). The slider had to be moved to the top of the scale, if the syllable was rated maximally prominent. In case of a completely non-prominent syllable, the slider had to be kept in the lowest position. The subjects where encouraged to use the full range of the sliders.

In a training phase, the subjects were familiarized with the experimental setting. Then, six test-sentences were rated, followed by a distraction task. In the following priming stage we presented 24 sentences with equal

ExLing 2008: Proceedings of 2nd Tutorial and Research Workshop on Experimental Linguistics, 25-27 August 2008, Athens, Greece 
syntactic and similar semantic structure for each of the initial test-stimuli. All priming sentences belonging to one test sentence shared the prosodic pattern. However, this differed from the pattern of the pertinent test sentence in the accentuation of one particular syllable. The test-sentences where presented again in the last test stage. If the priming is successful a significant difference between the first and second rating of the test sentences should be the result.

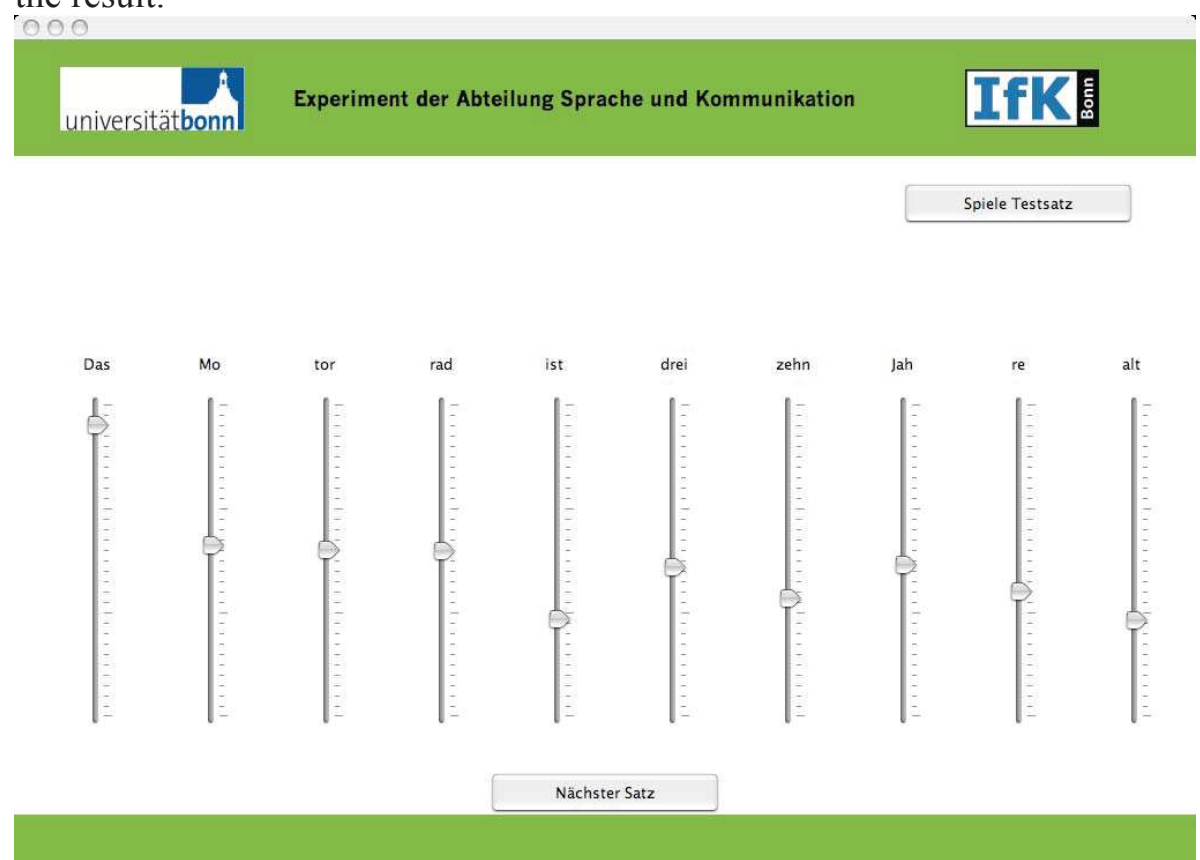

Figure 1. The GUI for the prominence rating.

One finding is that the average ratings of test sentences were much lower in the second rating. (cf. Figure 2 for an example)

Table 1. Results of Experiment 1.

\begin{tabular}{|l|l|}
\hline Condition $\mathrm{A}$ & Condition $\mathrm{B}$ \\
\hline $\begin{array}{l}\text { Sentence } 1 \\
\mathrm{t}(31)=2.11, \mathrm{p}<.05\end{array}$ & $\begin{array}{l}\text { Sentence } 1 \\
\mathrm{t}(31)=0.9, \mathrm{p}=.8125\end{array}$ \\
\hline $\begin{array}{l}\text { Sentence } 2 \\
\mathrm{t}(31)=2.0271, \mathrm{p}<.05\end{array}$ & $\begin{array}{l}\text { Sentence } 2 \\
\mathrm{t}(31)=1.6515, \mathrm{p}=.9456\end{array}$ \\
\hline $\begin{array}{l}\text { Sentence 3 } \\
\mathrm{t}(31)=1.9823, \mathrm{p}<.05\end{array}$ & $\begin{array}{l}\text { Sentence 3 } \\
\mathrm{t}(31)=2.1573, \mathrm{p}=.9806\end{array}$ \\
\hline
\end{tabular}


CONDITION B SENTENCE 2

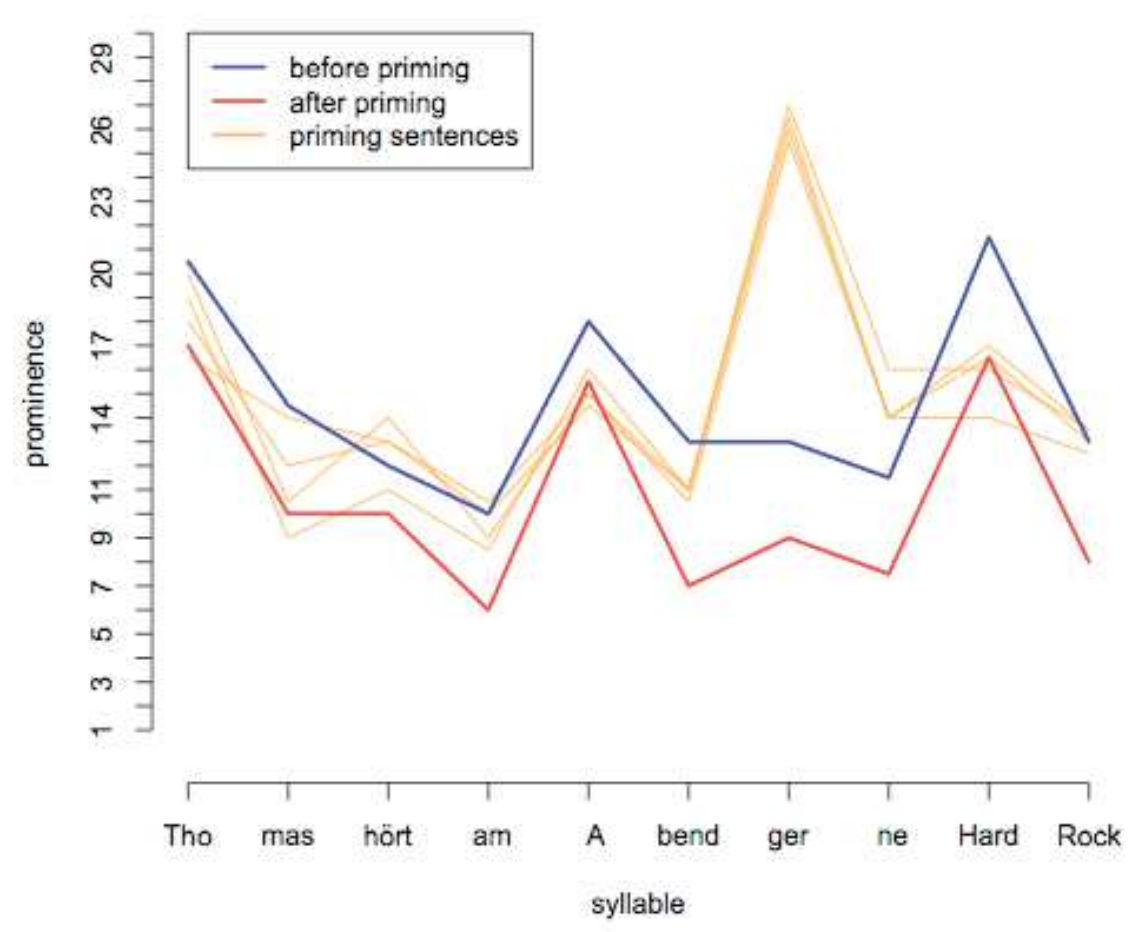

Figure 2. Prominence rating. A test sentence in condition B.

The manipulated syllables show the predicted difference. The results look promising, if one looks only at the manipulated syllable. When looking at the differences between the manipulated sentences and their neighbors, no significant difference is found. This lead to the second experiment where we used a four group design. This should help to avoid a repetition of the presentation of the test sentence and make the duration of the experiment much shorter.

\section{Experiment 2}

For this experiment 72 subjects where asked to rate the syllable prominence of 20 sentences. The same interface was used for presentation and rating as in the first experiment.

There were two conditions with two groups. Each group was primed with a different set of priming material and exposed to the same test sentence in the end of the test. The test sentences where compared. 
We mostly found significant differences in the ratings in both conditions. (cf. Table 2) In the group, where the priming material contained one stressed syllable, we found that the ratings of the not manipulated syllables where lower than in the other group for condition A.

Table 2. Results of Experiment 2.

\begin{tabular}{|l|l|}
\hline Condition A & Condition B \\
\hline $\begin{array}{l}\text { Sentence } 1 \\
\mathrm{t}(33.65)=-3.5608, \mathrm{p}<.01\end{array}$ & $\begin{array}{l}\text { Sentence } 1 \\
\mathrm{t}(33.529)=2.0652, \mathrm{p}<.05\end{array}$ \\
\hline $\begin{array}{l}\text { Sentence } 2 \\
\mathrm{t}(27.353)=-2.1909, \mathrm{p}<.05\end{array}$ & $\begin{array}{l}\text { Sentence } 2 \\
\mathrm{t}(31.096)=-0.0365, \mathrm{p}=.5144\end{array}$ \\
\hline $\begin{array}{l}\text { Sentence } 3 \\
\mathrm{t}(28.297)=-1.6834, \mathrm{p}=.05165\end{array}$ & $\begin{array}{l}\text { Sentence 3 } \\
\mathrm{t}(31,737)=2.156, \mathrm{p}<.05\end{array}$ \\
\hline $\begin{array}{l}\text { Sentence } 4 \\
\mathrm{t}(24.103)=-1.8616, \mathrm{p}<.05\end{array}$ & $\begin{array}{l}\text { Sentence } 4 \\
\mathrm{t}(32.835)=0.7846, \mathrm{p}=.2192\end{array}$ \\
\hline
\end{tabular}

\section{Conclusion and Outlook}

We were able to show, that the priming paradigm is well suitable for the research of top-down expectations. The results of this study give further support to the hypothesis, that top-down expectations have an impact an the rating of syllable prominence.

Further studies will look how different words and positions alter the effect size. Another goal is the estimation of the amount of influence of the top-down expectation on the rating of syllable prominence.

\section{References}

Eriksson, A., Grabe E. And Traunmüller, H. 2002. Perception of syllable promi nence by listeners with and without competence in the tested language. Proceedings Speech Prosody 2002, Aix-en-Provence, 275-278.

Wagner, P. 2005. Great expactations - introspective vs. perceptual prominence ratings and their acoustic correlates. Proceedings of INTERSPEECH 2005, Lisbon, 2381-2384. 